Research Article

\title{
The Influence of End User Computing System (EUCS) on User Satisfaction: The Case of a Logistic and Courier Service Company
}

\author{
Rudzi Munap ${ }^{1}$, Siti Nor Bayaah Ahmad ${ }^{2}$, Sofhinaz Abdul Hamid ${ }^{3}$, Mirza Fareed Beg MM Talib Beg ${ }^{4}$ \\ 1,2,3,4 UNITAR International University
}

\begin{abstract}
In any service and product delivery organizations, front-line employees play a key role in interacting with customers. The organization seek information from the customers; make sense of the information and by using an information system provided they further act to meet customer demands. The interactions between front-line employees and customers influence the overall perception of the service quality and ultimately, customer satisfaction within the services context. This is because services are characterized by inseparability and intangibility, and it is often the employees themselves who deliver the service and act as a communication channel. Since satisfied employees are likely to treat customers better and offer an improved service, it is vital for an organization to understand the needs and expectations of their employees to increase their level of satisfaction. The present study employed one of the main logistic and courier services in Malaysia by evaluating the effectiveness and efficiency of its over-the-counter system, using the original model Doll and Torkzadeh (1988). A self-administered questionnaire were distributed to 234 employees located at selected branches in Klang Valley, Malaysia. Findings indicated that among the five dimensions of users' satisfaction namely content, accuracy, format and timeliness; show positive significant relationship with the user's satisfaction. Only ease-ofuse indicated no significant relationship. It has proven that front-line employees play a significant role in the overall service rating, organizations should be more considerate and provide attention in managing their performance. The findings of the study can provide valuable information to postal organizations that have adopted or are thinking about adopting a new retail system. These postal organizations will have better opportunity to gain insights in order to make the adoption successful as they get to know how end users perceive content, accuracy, format, ease of use and timeliness of the system.
\end{abstract}

\section{Keywords: User Satisfaction; Information System; End User Computing Satisfaction}

\section{Introduction}

Organizations need to focus on delivering the best customer experience for their regular clients, wowing them into realizing they made the right choice in doing business with the organizations. In any service and product delivery organizations, front-line employees play a key role in interacting with the customers. In the customers' eyes, the organization that is represented by frontline employees can have an impact on the organization image and reputation. The customer's desire could be met when the frontline employees provide good or quality services. With this, the organization gains a positive reputation, hence that could give them a competitive edge (Wilson et al., 2008).

The research done by Gounaris (2008) highlighted that interactions between frontline employees and customers influence the overall perception of the service quality and ultimately, customer satisfaction within the services context. This is due to the fact that services are characterized by inseparability and intangibility, and it is the employees themselves who deliver the service and act as a communication channel (Berry, 1981; Cadwaller et al., 2010; Paswan et al., 2005). Similarly, Allen and Grisaffe (2001) and Tharenou, Shaks, and Moore (2007) said that employees with a positive attitude and feel satisfied are able to perform better, which in turn favours organization results. Since satisfied employees are likely to treat customers better, offer and improved service, it is vital for an organization to understand the needs and expectations of their employees to increase their level of satisfaction, (Ahmed \& Rafiq, 2003; Berry, Hensel, \&Burke, 1976; Paswan et al., 2005; Wieseke, Ahearne, Lam \& Van Dick, 2009).

As is proven, frontline employees play a significant role in the overall service rating, organizations should be more considerate and provide attention in managing their performance. The beginning of information technology and information systems has changed management structure, functions and style of business planning and implementation. It is not just tools to record and process data, but an essential part in the process of decision support that improves performance (Yassin, 2006). Therefore, using a system will enhance job performance, productivity, efficiency and quality of work. Businesses today face a stark reality: anticipate, respond, and react to the growing demands of the marketplace, or perish. In a fiercely competitive environment, business strategy not only determines success, it governs business survival. Now, more than ever, effective business strategy centres on aggressive, efficient use of information technology. Information system plays a significant role in aiding it to 
Siti Nor Bayaah Ahmad et al/ The Influence of End User Computing System (EUCS) on User Satisfaction: The Case of a Logistic and Courier Service Company

adopt and maintain a strategic position of an organization. Information system in large scale permits an organization to intensely improve their business model, change internal structures and over time, increase profit margins (Lucas, 2005).

\section{Literature Review}

\subsection{The underpinning theory}

Doll and Torkzadeh in 1988, created the EUCS model to measure the factors that affect users' satisfaction of computerbased Information System (IS). EUCS model is the extension of User Information Satisfaction (UIS) model, which was developed by Ives, Olson and Baroudi in 1983. As a standard measurement of EUCS (Doll \& Torkzadeh, 1988), developed a multifaceted 12-item instrument, which requires the end users' subjective perceptions of the five end-user satisfaction components, namely content; accuracy; format; ease of use; and timeliness, to measure EUCS.

\begin{tabular}{|c|c|}
\hline Factor & Definition \\
\hline Content & "The comprehenensiveness of the information content" \\
\hline Accuracy & "The correctness of the output information" \\
\hline Format & "The material design of the layout and display of the output contents" \\
\hline Ease of use & $\begin{array}{l}\text { "The ease or difficulty with which the user may act to utilize the capability of the } \\
\text { computer system" }\end{array}$ \\
\hline Timeliness & "The arailability of the output information at a time suitable for its use" \\
\hline
\end{tabular}

Figure 2.1 Definitions of EUCS model by Doll and Torkzadeh (1988)

Across a variety of IS applications, Doll and Torkzadeh (1988) model was defined as reliable and valid. Subsequently, as an empirical tested model, EUCS model is accepted as a reliable model and able to determine the information system success regarding end-user's satisfaction.

Past studies measure EUCS of different computer-based systems, such as ERP, MIS, CAS, HIS and BI\&A (Deng, Doll, Al-Gahtani,; Ilias, et al., 2009; Aggelidis \& Chatzoglou, 2012; Hou, 2012). Many of these studies have redefined or extended the EUCS model to serve their needs and new emerging technologies aspects. EUCS model has been used in evaluating user satisfaction of various systems and in different ways to interpret different technology aspects.

\subsection{End user satisfaction of PRS}

User satisfaction has been investigated since end-user computing (EUC) was established as a term. EUC refers to the changing role of users who used to co-operate with programmers to get information from a computer system, to their evolution as end users who directly interacted with the computer system in order to enter information and prepare output report (Davis \& Olson, 1984).

Yet, according to Doll and Torkzadeh (1988), user satisfaction is "an affective attitude towards a specific computer application by someone who interacts with the application directly". Doll and Torkzadeh (1988) defined user satisfaction as an emotional attitude that had five dimensions, content, accuracy, format, ease of use, and timeliness. This 12-item instrument is known as End-User Computing Satisfaction Instrument,

It can be concluded that if the users are well satisfied with the system as they use it, the system will be working fine. User satisfaction has been widely employed in practice as a surrogate measure of information systems effectiveness. Users' perceived satisfaction in multiple aspects of the systems was significantly correlated with their responses to the organizational effectiveness. On the other hand, Swanson (1974) identified a high level of correlation between the users' perceived system satisfaction and their applications of the system outputs.

\subsection{The relationship between variables}

\subsubsection{Relationship Between Content and User Satisfaction}

The use of information system reports is one of the most frequently reported measures of the success of an information system. The end user perceived that the content of information is important especially for decision-making process. In the study by Rivard and Huff (1988), they evaluated the usefulness of the content produced by information system, which is user developed, among 272 end-users. Edmundson and Ross (1994) suggested measuring system characteristics such as content of the database, aggregation of details, human factors, response time and system accuracy. In Doll and Torkzadeh study, they labelled content of information as the most important dimension in evaluating EUCS. They also suggested that content is one of the factors that represent the overall EUCS. Thus, this study hypothesised that:

$\mathrm{H}_{1}=$ There is a significant relationship between content and user satisfaction of PRS.

\subsubsection{Relationship between Accuracy and User Satisfaction}

Accuracy of information produced by the system is important to measure the overall EUCS. Consequently, it will lead to end user overall satisfaction. Bailey and Pearson (1983) proposed 39 system-related items for measuring user satisfaction. Among their ten most important items, in descending order of importance, were information accuracy, output, timeliness, reliability, completeness, relevance, precision, and currency. In the early study, Ahituv (1980) incorporated five information characteristics into a multi-attribute utility measure of information value namely accuracy, timeliness, relevance, aggregation and formatting. Also, Olson and Lucas (1982) reported accuracy and appearance as a measure of information quality in office automation systems. Subsequently, it seems to suggest that accuracy is one of the factors that represent the overall EUCS. The respondent who 
Siti Nor Bayaah Ahmad et al/ The Influence of End User Computing System (EUCS) on User Satisfaction: The Case of a Logistic and Courier Service Company

is satisfied with the accuracy of information is also satisfied with overall system. Thus, the study hypothesised that:

$\mathrm{H}_{2}=$ There is a significant relationship between accuracy and user satisfaction of PRS.

\subsubsection{Relationship between Format and User Satisfaction}

Bailey and Pearson (1983) classified format of information reported as the one of the description measures in their study. Doll and Torkzadeh (1988) used format in their study as the second dimensions in determining EUCS. Mihir and Bijan (2002) identified six relevant dimensions (relevance, confidence, usefulness, ease of use, format and playfulness) of user satisfaction under a research framework for user satisfaction with decision support and usability of a system. End user is expected to satisfy with the format of report produced by the system. Thus, the study expects that the satisfaction with the format of the report might have the relationship with the overall satisfaction. Therefore, we hypothesised that:

$\mathrm{H}_{3}=$ There is a significant relationship between format and user satisfaction of PRS.

\subsubsection{Relationship between Ease of Use and User satisfaction}

Ease of use has become increasingly important in software design. There is increasing evidence that the effective functioning of an application depends on its ease of use or usability. If end users find an application easy to use, they may become more advanced users, and therefore, better able to take an advantage of the range of capabilities the software has to offer. Also, ease of use may improve productivity or enable decision makers to examine more alternatives (Doll and Torkzadeh, 1988). Ease of use is expected to increase the level of overall EUCS. It shows that ease of use is one of the factors that represent the overall EUCS. The respondent who is satisfied with ease of use of the system is expected to satisfy with overall system. Thus, the hypothesis is:

$\mathrm{H}_{4}=$ There is a significant relationship between ease of use and user satisfaction of PRS.

\subsubsection{Relationship between Timeliness and User satisfaction}

According to Chang et al. (2015), timeliness is referring to the speed and frequency of information provided by accounting information system (AIS). Miller and Doyle (1987) conducted studies and employed report timeliness as their descriptions of measures. In general, if the end-users satisfy with the timeliness of the report produced by the CAS, they may be satisfied with the overall of the system. Hence, timeliness is assumed to increase the level of overall EUCS. This study suggests that timeliness is one of the factors that represent the overall EUCS. Thus, the study hypothesised that:

$\mathrm{H}_{5}=$ There is a significant relationship between timeliness and user satisfaction of PRS.

\subsection{Conceptual framework}

The proposed conceptual framework is adopted from an original model developed by Doll and Torkzadeh (1988). The original model of Doll and Torkzadeh (1988) proposed five quality dimensions, which influence end user satisfaction: content, accuracy, format, ease of use and timeliness. In this study, dependent variable (DV) is End User Satisfaction and independent variables (IV) are content, accuracy, format, ease of use and timeliness.

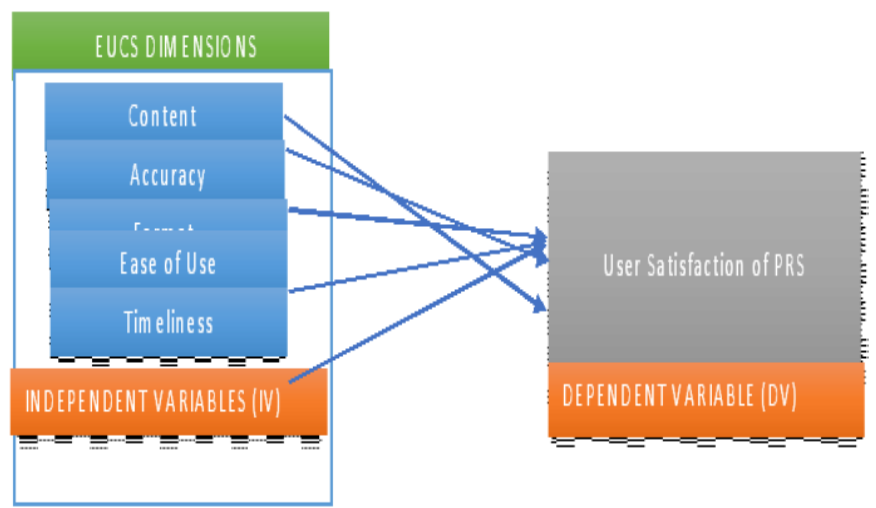

Figure 2.2Conceptual Framework illustrating the EUCS Dimensions and User Satisfaction of PRS adopted by Doll and Torkzadeh (1988) model

\section{Methodology}

A descriptive analytical research design using the quantitative approach is considered as the most appropriate method for data collection as it is fast and economical. A self-completed questionnaire was developed to obtain required information from the respondents using simple random technique. In order to simplify the process of determining the sample size for a population, reference was made to a Table in Determining Sample Size by Krejcie and Morgan (1970), resulting a sample size of 201. For pilot testing, the questionnaire was distributed to 30 respondents who have one year or more experience in using PRS. Apart from responding to the questionnaire, the respondents were asked to provide feedback such as suggestions which would help to increase the quality of the questionnaire. Some of the problems highlighted after the pilot testing involved redundancy of questions, length of introduction, unclear words because of the translation from English to Bahasa Malaysia and spelling mistakes. Based on the suggestions provided, the questionnaire was improved.

From the reliability analysis for 30 respondents as shown in Table 3.1, all factors including independent and dependent variables are deemed reliable. The Cronbach's Alpha for content, accuracy, format, ease of use and timeliness which is above 0.7 are acceptable. It can be concluded that all these five independent variables have influence on user satisfaction. Accuracy has a high level of internal consistency as determined by Cronbach's Alpha value of 0.945 .

Table 3.1 Cronbach's Alpha Reliability Test for variables

\begin{tabular}{|l|l|l|}
\hline Construct & Cronbach's Alpha & No of Items \\
\hline Content & 0.903 & 10 \\
\hline Accuracy & 0.945 & 8 \\
\hline Format & 0.922 & 7 \\
\hline Ease of Use & 0.934 & 7 \\
\hline
\end{tabular}


Siti Nor Bayaah Ahmad et al/ The Influence of End User Computing System (EUCS) on User Satisfaction: The Case of a Logistic and Courier Service Company

\begin{tabular}{|l|l|l|} 
Timeliness & 0.884 & 7 \\
\hline User Satisfaction & 0.953 & 6 \\
\hline
\end{tabular}

The Cronbach's Alpha values of all constructs were measured and presented in Table 3.1. All constructs values are above 7.0 threshold, ranging from 0.884 to 0.953 . This study has a satisfactory level of reliability measurement (Nunnally, 1978).

\section{$4 \quad$ Method of analysis}

For the demographic part, descriptive analysis was mainly performed. This kind of analysis were used in order to be able to interpret data such as work position and use of PRS and variations among male and female users. Moving on to the second part of questionnaire both descriptive and inferential analysis was conducted. Descriptive analysis, specifically univariate and bivariate analysis (Bhattacherjee, 2012), was conducted. Through univariate analysis, the study was able to check the frequency distribution, the mean and the standard deviation of each construct's item, as well as the overall mean of each construct (Bhattacherjee, 2012). On the other hand, by using bivariate analysis, the study could check the interrelationships between the constructs, consequently a bivariate correlation statistical analysis was conducted (Bhattacherjee, 2012).

\subsection{Profile of respondents}

For the work position, the responses were divided into five groups, which is Branch Manager, Assistant Branch Manager, Cashier, Supervisor and Teller. However, the respondents only consist of Branch Manager, Supervisor and Teller. The proportions of the work position are $4.7 \%$, 9\% and $86.3 \%$ respectively. In terms of gender, it shows that the female respondents are 161, which represents $68.8 \%$ of the total respondents. In comparison to that, the male respondents are just half of the number which is 73 at $31.2 \%$ from the total. As for age, almost half of the respondents are from the age of $18-30$ which is $47.9 \%$. Subsequently, the respondents came from the age group of 31-40 which represents $34.2 \%$ of the total. The remaining respondents came from the age group of 41-50 and 51-60 which is 9\% respectively.

The respondents educational level noted only their secondary or diploma qualification, which represents $65.4 \%$ and $34.6 \%$ respectively. Concerning the respondents experience in using PRS, the experience from 1 to 2 years and above 2 years are almost equal where $51.7 \%$ of the respondents has experience from 1 to 2 years while $48.3 \%$ have experience above 2 years. On PRS system usage, $91.5 \%$ of the respondents are using PRS on daily basis. This can be explained by looking at the number of the tellers responded which is $86.3 \%$. Tellers use PRS system every day at the counter.

Table 4.1Demographic Profile of Respondents

\begin{tabular}{|c|c|c|c|}
\hline Category & Item & Frequency & Percentage \\
\hline \multirow[t]{5}{*}{ Work Position } & Branch Manager & 11 & $4.7 \%$ \\
\hline & Assistant Branch Manager & 0 & $0 \%$ \\
\hline & Cashier & 0 & $0 \%$ \\
\hline & Supervisor & 21 & $9.0 \%$ \\
\hline & Teller & 202 & $86.3 \%$ \\
\hline \multirow[t]{2}{*}{ Gender } & Male & 73 & $31.2 \%$ \\
\hline & Female & 161 & $68.8 \%$ \\
\hline \multirow[t]{4}{*}{ Age } & $18-30$ & 112 & $47.9 \%$ \\
\hline & $31-40$ & 80 & $34.2 \%$ \\
\hline & $41-50$ & 21 & $9.0 \%$ \\
\hline & $51-60$ & 21 & $9.0 \%$ \\
\hline \multirow[t]{4}{*}{ Education Level } & Secondary & 153 & $65.4 \%$ \\
\hline & Diploma & 81 & $34.6 \%$ \\
\hline & Degree & 0 & $0 \%$ \\
\hline & Master & 0 & $0 \%$ \\
\hline \multirow[t]{3}{*}{ PRS Experience } & Less than 1 year & 0 & $0 \%$ \\
\hline & 1-2 years & 121 & $51.7 \%$ \\
\hline & Above 2 years & 113 & $48.3 \%$ \\
\hline \multirow[t]{3}{*}{ PRS system's use each week } & Once a week & 0 & $0 \%$ \\
\hline & Several times a week & 20 & $8.5 \%$ \\
\hline & Daily & 214 & $91.5 \%$ \\
\hline
\end{tabular}


Siti Nor Bayaah Ahmad et al/ The Influence of End User Computing System (EUCS) on User Satisfaction: The Case of a Logistic and Courier Service Company

\subsection{Pearson correlation tests analysis}

Table 4.2 below describes the Rule of Thumb for Interpreting the Size of a Correlation Coefficient by Hinkle and Wiersma (2003).

Table 4.2Rule of Thumb for Interpreting Size of Correlation Coefficient

\begin{tabular}{|c|c|}
\hline Size of Correlation & Interpretation \\
\hline .90 to $1.00(-.90$ to -1.00$)$ & High positive (negative) correlation \\
\hline .70 to $.90(-.70$ to -.90$)$ & Moderate positive (negative) correlation \\
\hline .50 to $.70(-.50$ to -.70$)$ & Low positive (negative) correlation \\
\hline .30 to $.50(-.30$ to -.50$)$ & negligible correlation \\
\hline .00 to $.30(.00$ to -.30$)$ & \\
\hline
\end{tabular}

Table 4.3 Pearson Correlation

\begin{tabular}{|c|c|c|c|c|c|c|c|}
\hline \multicolumn{8}{|c|}{ Correlations } \\
\hline & & CONTENT & ACCURACY & FORMAT & EASEOFUSE & TIMELINESS & USER SATISFACTION \\
\hline \multirow[t]{3}{*}{ CONTENT } & Pearson Correlation & 1 & $.919^{-1}$ & $.723^{-4}$ & $.616^{-*}$ & $.670^{-1}$ & $.956^{*}$ \\
\hline & Sig. (2-tailed) & & .000 & .000 & .000 & .000 & .000 \\
\hline & $\mathrm{N}$ & 234 & 234 & 234 & 234 & 234 & 234 \\
\hline \multirow[t]{3}{*}{ ACCURACY } & Pearson Correlation & $.919^{-1}$ & 1 & $.814^{-1}$ & $.669^{*-}$ & $.708^{*-1}$ & $.973^{*}$ \\
\hline & Sig. (2-tailed) & .000 & & .000 & .000 & .000 & .000 \\
\hline & $\mathrm{N}$ & 234 & 234 & 234 & 234 & 234 & 234 \\
\hline \multirow[t]{3}{*}{ FORMAT } & Pearson Correlation & $.723^{-1}$ & $.814^{-1}$ & 1 & $.808^{*-}$ & $.755^{\circ}$ & $.781^{\prime \prime}$ \\
\hline & Sig. (2-tailed) & .000 & .000 & & .000 & .000 & .000 \\
\hline & $\mathrm{N}$ & 234 & 234 & 234 & 234 & 234 & 234 \\
\hline \multirow[t]{3}{*}{ EASEOFUSE } & Pearson Correlation & $.616^{*-1}$ & $.669^{-1}$ & $.808^{-1}$ & 1 & $.506^{*-1}$ & $.649^{*}$ \\
\hline & Sig. (2-tailed) & .000 & .000 & .000 & & .000 & .000 \\
\hline & $\mathrm{N}$ & 234 & 234 & 234 & 234 & 234 & 234 \\
\hline \multirow[t]{3}{*}{ TIMELINESS } & Pearson Correlation & $.670^{-1}$ & $.708^{-1}$ & $.755^{*-1}$ & $.506^{*-}$ & 1 & $.666^{2}$ \\
\hline & Sig. (2-tailed) & .000 & .000 & .000 & .000 & & .000 \\
\hline & $\mathrm{N}$ & 234 & 234 & 234 & 234 & 234 & 234 \\
\hline \multirow[t]{3}{*}{ SATISFACTION } & Pearson Correlation & $.956^{-1}$ & $.973^{-1}$ & $.781^{-1}$ & $649^{-*}$ & $.666^{*-1}$ & 1 \\
\hline & \begin{tabular}{|l|} 
Sig. (2-tailed) \\
\end{tabular} & .000 & .000 & .000 & .000 & .000 & \\
\hline & $\mathrm{N}$ & 234 & 234 & 234 & 234 & 234 & 234 \\
\hline
\end{tabular}

${ }^{\star *}$. Correlation is significant at the 0.01 level (2-tailed).

A strong linear correlation was observed between Accuracy and User Satisfaction where the Pearson correlation is 0.973. When Pearson correlation is close to 1, this means that there is a strong relationship between Accuracy and User Satisfaction. The same was observed between Content and User Satisfaction at Pearson correlation of 0.956. Meanwhile, moderate linear correlation was observed between Format, Timeliness, Ease of Use and User Satisfaction at Pearson correlation with $0.781,0.666$ and 0.649 respectively.

Meanwhile, all the Sig 2 tailed value $\mathrm{p}$, is 0.00 for all the variables. If the $\mathrm{p}$ value is less than or equal to 0.05 , it can be concluded that there is a statistically significant correlation between Content, Accuracy, Format, Ease of Use, Timeliness and User Satisfaction. That means, increases or decreases in one independent variable do significantly relate to increases and decreases in the dependent variable.

\subsubsection{Linear regression}

Linear regression is used to determine the extent to which there is a linear relationship between a dependent variable and one or more dependent variables. There are two types of linear regression, simple linear regression and multiple linear regression.

\subsubsection{Multiple linear regression}


Siti Nor Bayaah Ahmad et al/ The Influence of End User Computing System (EUCS) on User Satisfaction: The Case of a Logistic and Courier Service Company

In multiple linear regression, two or more independent variables are used to predict the value of a dependent variable. The difference between the two is the number of independent variables. In both cases there is only a single dependent variable. Multiple regression analysis was performed in this study. Table 4.4 presents the result of model summary that content, accuracy, format, ease of use and timeliness predict the user satisfaction of PRS.

Table 4.4 Model Summary

Model Summary

\begin{tabular}{|l|l|l|l|l|l|}
\hline Model & $\mathrm{R}$ & R Square & Adjusted R Square & Std. Error of the Estimate & Durbin-Watson \\
\hline 1 & $.987^{\mathrm{a}}$ & .974 & .973 & .09507 & 2.276 \\
\end{tabular}

a. Predictors: (Constant), TIMELINESS, EASE OF USE, CONTENT, FORMAT, ACCURACY

b. Dependent Variable: USER SATISFACTION

From this model, R represents the simple correlation 0.987 and $\mathrm{R}$ Square is 0.974 , which shows $97.4 \%$ changes in user satisfaction can be explained by content, accuracy, format, ease of use and timeliness. However, $2.6 \%$ changes can also be explained by other variables that influence the level of satisfaction.

The result of Adjusted R Square tested shows that content, accuracy, format, ease of use and timeliness contribute significantly $(\mathrm{F}=1680.174 ; \mathrm{p}<0.001)$ as shown in Table 4.5 and predict $97.3 \%$ of variation in user satisfaction.

Table 4.5 ANOVA

ANOVA $^{\mathrm{a}}$

\begin{tabular}{|ll|l|l|l|l|l|}
\hline Model & & Sum of Squares & df & Mean Square & F & Sig. \\
\hline \multirow{2}{*}{1} & Regression & 75.932 & 5 & 15.186 & 1680.174 \\
& Residual & 2.061 & 228 & .009 & & \\
& Total & 77.992 & 233 & & & \\
\hline
\end{tabular}

a. Dependent Variable: USER SATISFACTION

b. Predictors: (Constant), TIMELINESS, EASE OF USE, CONTENT, FORMAT, ACCURACY

Table 4.6 meanwhile presents properties of casual paths, including standardized coefficients beta, $t$ values and significant results, for each equation in the hypothesised model.

Table 4.6 Coefficient between EUCS dimensions and user satisfaction of PRS

Coefficients $^{\mathrm{a}}$

\begin{tabular}{|c|c|c|c|c|c|c|}
\hline \multirow{2}{*}{\multicolumn{2}{|c|}{ Model }} & \multicolumn{2}{|c|}{ Unstandardized Coefficients } & \multirow{2}{*}{$\begin{array}{l}\text { Standardized } \\
\text { Coefficients } \\
\text { Beta }\end{array}$} & to & \multirow[t]{2}{*}{ Sig. } \\
\hline & & B & Std. Error & & & \\
\hline \multirow{6}{*}{1} & (Constant) & -.124 & .039 & & -3.171 & .002 \\
\hline & CONTENT & .396 & .027 & .416 & 14.823 & .000 \\
\hline & ACCURACY & .673 & .036 & 617 & 18.781 & .000 \\
\hline & FORMAT & .067 & .028 & .067 & 2.406 & .017 \\
\hline & EASEOFUSE & -.029 & .017 & -.032 & -1.642 & .102 \\
\hline & TIMELINESS & -.062 & .013 & -.084 & -4.715 & .000 \\
\hline
\end{tabular}

a. Dependent Variable: USER SATISFACTION

\subsubsection{Summary of research questions and hypotheses}

Table 4.7 below shows the summary for research questions and hypotheses of the study.

Table 4.7 Summary Table for Research Questions and Hypotheses

\begin{tabular}{|l|l|}
\hline Research Questions and Hypotheses & Result \\
\hline Research Question 1: Does the content influence user satisfaction of PRS? & Yes \\
\hline $\mathrm{H}_{1:}$ There is a significant influence between content and end user satisfaction of PRS. & Supported \\
\hline Research Question 2: Does the accuracy influence user satisfaction of PRS? & Yes \\
\hline $\mathrm{H}_{2}$ There is a significant influence between accuracy and end user satisfaction of PRS. & Supported \\
\hline
\end{tabular}


Siti Nor Bayaah Ahmad et al/ The Influence of End User Computing System (EUCS) on User Satisfaction: The Case of a Logistic and Courier Service Company

\begin{tabular}{|l|l|}
\hline Research Question 3: Does the format influence user satisfaction of PRS? & Yes \\
\hline $\mathrm{H}_{3:}$ There is a significant influence between format and end user satisfaction of PRS. & Supported \\
\hline Research Question 4: Does the ease of use influence user satisfaction of PRS? & No \\
\hline $\mathrm{H}_{4:}$ There is a significant influence between ease of use and end user satisfaction of PRS. & Not Supported \\
\hline Research Question 5: Does the timeliness influence user satisfaction of PRS? & Yes \\
\hline $\mathrm{H}_{5:}$ There is a significant influence between timeliness and end user satisfaction of PRS. & Supported \\
\hline $\begin{array}{l}\text { Research Question 6: Which of the five factors (content, accuracy, format, ease of use and } \\
\text { timeliness) contribute the most towards user satisfaction of PRS? }\end{array}$ & Accuracy \\
\hline
\end{tabular}

\subsection{Discussion on hypotheses testing}

The result shows that Hypothesis 1 (Content), Hypothesis 2 (Accuracy), Hypothesis 3 (Format) and Hypothesis 5 (Timeliness) have significant effect with user satisfaction. The significant relationship was found between accuracy and user satisfaction of PRS, $(\beta=0.617, t=18.781, p=0.000)$. This factor will be the most critical factor that contributes in user satisfaction and it seems that user perceived that accuracy of information produced by the system is important as it provides reliable, accurate and error free information. This result supports to accept Hypothesis 2. Another factor that contributes the most in the user satisfaction is content $(\beta=$ $0.416, t=14.823, p=0.000)$ because content of information is important especially for decision-making process. As a result, Hypothesis 1 is accepted.

Hypothesis 5 is accepted according to result $(\beta=-0.084, \mathrm{t}=-$ $4.715, \mathrm{p}=0.000)$. This factor contribute in user satisfaction as timeliness is about the length of time taken for information to be delivered to users. This is crucial as the delay of information delivery will result in dissatisfaction among customers at the counters and directly will affect the user satisfaction of PRS. Hypothesis 3 indicated that format of the PRS has significant relationship with user satisfaction. The result shows that format of the system on the user satisfaction is substantiated $(\beta=0.067, \mathrm{t}=2.406, \mathrm{p}=0.017)$. This is because most of the users are satisfied with the format of PRS and the format is expected to influence user satisfaction.

Hypothesis 4 (Ease of Use) were also constructed to examine the significant relationship with user satisfaction. Hypothesis 4 asserts that ease of use has significant relationship on user satisfaction. However, the result shows that the ease of use has insignificant effect with user satisfaction $(\beta=-0.032, \mathrm{t}=$ $1.642, \mathrm{p}=0.102)$. The result shows insignificant because all the users perceived that a new system is better in term of ease of use and more user friendly compared to the old system. Therefore, this factor has not really improved their satisfaction.

\section{Conclusion}

This study attempted to measure the user satisfaction of PRS using multiple regression by determining the significant effect of five factors that influence user satisfaction. Overall, this study indicates the most of end users have average satisfaction with PRS. It can be explained with descriptive result, which indicates average satisfaction for each of the EUCS dimension. Additionally, this study has enabled to identify the most critical factor that influences user satisfaction of PRS. The results show that accuracy, content and timeliness have significant effect on user satisfaction.

Today's fast IT progress and its impact on the various aspects of social dynamics naturally demands the rise of creative people, capable of accessing to diverse information sources, the processing, and communicating the information as needed. In general, problems with information system remain unnoticeable until they cause the system to fail. Routine system evaluation along with surveys of user satisfaction therefore is vital for the system to succeed. However, most companies would put more emphasis on technological upgrading of the system. Considering the main objective of PRS is servicing the public, routine evaluation on system and user satisfaction on how users feel about the system should be paid due attention.

\section{$5.1 \quad$ Contribution of the study}

The findings from this study are beneficial to both researchers and practitioners. For researchers, the major contribution of this study will be rigorously validating EUCS (Doll \& Torkzadeh, 1998) which enable researchers to use the EUCS model with increased confidence. Meanwhile, with a validated instrument, further research can be conducted in other area of applications and technological innovation. As a result of this study, EUCS can be better understood and applied to advanced information system as a standardized measure. Practitioners meanwhile can use the findings of this study with more confidence in usability testing when designing a new information system. System business analyst can also use the results to discern differences in satisfaction across target user groups during system, requirement gatherings. For example, rating for Content, Accuracy, Format, Ease of Use and Timeliness may differ based on user experience.

\section{References}

[1] Paswan, L. Pelton, S. True. (2005). Perceived managerial sincerity, feedback-seeking orientation and motivation among front-line employees of a service organization. 
Siti Nor Bayaah Ahmad et al/ The Influence of End User Computing System (EUCS) on User Satisfaction: The Case of a Logistic and Courier Service Company

Journal of Services Marketing, 19, 3-12.

[2] Allen, D. Grisaffe. 2001. Employee commitment to the organization and customer reactions: Mapping the linkages. Human Resource Management Review, 11, 209236.

[3] Aggelidis, V. P., \& Chatzoglou, P. D. (2012). Hospital information systems: Measuring end user computing satisfaction (EUCS). Journal of biomedical informatics, 45(3), 566-579.

[4] Bailey, J. E., \& Pearson, S. W. (1983). Development of a tool for measuring and analyzing computer user satisfaction. Management science, 29(5), 530-545.

[5] Bhattacherjee, A. (2012). Social science research: principles, methods, and practices.

[6] Berry L.L. (1981), "The employee as customers", Journal of Retail Banking, Vol.3-3, 8-25.

[7] Cadwallader, S., Jarvis, C. B., Bitner, M. J., \& Ostrom, A. L. (2010). Frontline employee motivation to participate in service innovation implementation. Journal of the Academy of Marketing Science, 38(2), 219-239.

[8] Chang, I. C., Chang, C. H., Wu, J. W., \& Huang, T. C. K. (2015). Assessing the performance of long-term care information systems and the continued use intention of users. Telematics and Informatics, 32(2), 273-281.

[9] Chou, M., \& Xu, J. (2012). Business intelligence in blogs: Understanding consumer interactions and communities. MIS quarterly, 36(4), 1189-1216.

[10] Davis, G. B., \& Olson, M. H. (1984). Management information systems: conceptual foundations, structure, and development. McGraw-Hill, Inc.

[11]Deng, X., Doll, W. J., Al-Gahtani, S. S., Larsen, T. J., Pearson, J. M., \& Raghunathan, T. S. (2008). A crosscultural analysis of the end-user computing satisfaction instrument: A multi-group invariance analysis. Information \& Management, 45(4), 211-220.

[12] Doll, W. J., \& Torkzadeh, G. (1988). The measurement of end-user computing satisfaction. MIS quarterly, 259-274.

[13] Gounaris S. (2008) The notion of internal market orientation and employee job satisfaction: some preliminary evidence. Journal of Services Marketing; 22(1):68-90.

[14]Hinkle DE, Wiersma W, Jurs SG. (2003). Applied Statistics for the Behavioral Sciences. 5th ed. Boston: Houghton Mifflin.

[15] Hou, C. K. (2012). Examining the effect of user satisfaction on system usage and individual performance with business intelligence systems: An empirical study of Taiwan's electronics industry. International Journal of Information Management, 32(6), 560-573.

[16] Ilias, A., Razak, M. Z. A., Rahman, R. A., \& Yasoa, M. R. (2009). End-user computing satisfaction (EUCS) in computerised accounting system (CAS): which the critical factors? A case in Malaysia. Computer and Information Science, 2(1), 18.

[17] Wieseke, M. Ahearne, S. Lam, R. Van Dick. (2009). The role of leaders in internal marketing. Journal of
Marketing, 73 (2009), 123-145.

[18] Berry, J. Hensel, M. Burke. (1976). Improving retailer capability for effective consumerism response. Journal of Retailing, 52, 3-14.

[19] Nunnally, J. C. (1978). Psychometric theory. McGrawHill.

[20] Ahmed, M. Rafiq. (2003). Internal marketing issues and challenges. European Journal of Marketing, 37, 11771186.

[21] Tharenou, A. Shaks, C. Moore. (2007). A review and critique of research on training and organizational-level outcomes. Human Resource Management Review, 17, 251-273.

[22] Robert V. Krejcie, Daryle W. Morgan. (1970). Determining Sample Size for Research Activities. Educational and Psychological Measurement, 30, 607610.

[23] Wilson, Timothy D., and Daniel T. Gilbert. 2008. Explaining away a model of affective adaptation. Perspectives on Psychological. Science 3(5): 370.

[24] Yassin, Ghalib. (2006). Decision support systems, the first edition, Dar Al Manahej, Amman, Jordan 